\title{
Earthquakes of the Caucasus
}

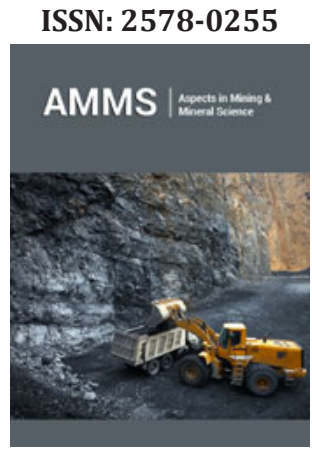

*Corresponding author: Burmin V Yu, Schmidt Institute of Physics of the Earth of the Russian Academy of Sciences, Russia

Submission: 監 December 02, 2019

Published: 侮 December 04, 2019

\section{Volume 4 - Issue 2}

How to cite this article: Burmin VY. Earthquakes of the Caucasus. Aspects Min Miner Sci.4(2). AMMS.000583.2019. DOI: 10.31031/AMMS.2019.04.000583

Copyright@ Burmin V Yu, This article is distributed under the terms of the Creative Commons Attribution 4.0 International License, which permits unrestricted use and redistribution provided that the original author and source are credited.

\section{Burmin VY*}

Schmidt Institute of Physics of the Earth of the Russian Academy of Sciences, Russia

\section{Opinion}

The previously obtained results on determining the location of the centers of crustal earthquakes in the Caucasus clearly indicate that the methods used to determine the earthquake hypocenters used in the seismic service do not allow accurately locating seismic events. In addition, the use of only one velocity column or one set of hodographs for determining earthquake hypocenters for all stations in the network also does not contribute to the exact determination of the position of earthquake hypocenters. In order to determine the position of the centers of earthquakes with high accuracy (Figure 1), it is necessary to have a fairly detailed idea of the deep structure of the earth's crust and upper mantle in the studied region. At the same time, it is advisable to take information about the region's structure not from earthquake data, but from other observations, for example, from deep seismic sounding (DSS). Based on seismological bulletins of the Caucasus for 1970-2015. The coordinates of the hypocenters of the earthquakes of the Caucasus were redefined. The general picture of the distribution of earthquake hypocenters in the Earth's crust of the Caucasus differs significantly from the distribution of hypocenters in the catalog.

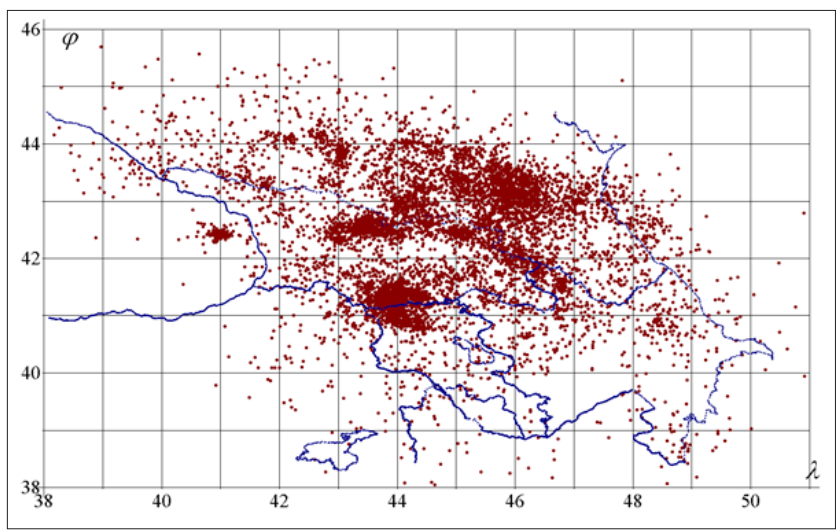

Figure 1: Distribution of epicenters of earthquakes in the Caucasus for the period 1971-2015.inance-area.

It is also shown that in the Caucasus, in addition to crustal earthquakes, rather deep mantle earthquakes occur. This fact, in addition to direct determinations, is confirmed by data published in catalogs and bulletins of the Caucasus. The question of the existence of foci of deep earthquakes in the Caucasus is extremely important both from the point of view of geodynamics and from the point of view of seismic hazard and seismic zoning of the region (Figure 2). It was previously believed that earthquakes may occur in the Caucasus, the depth of which does not exceed $150 \mathrm{~km}$. The existence of deeper earthquakes in the Caucasus was not previously discussed in the scientific literature, however, a discussion on this issue in recent years has been reflected in a number of works. The presence of foci of deep earthquakes in the Caucasus significantly changes our views on the structure and geotectonic of the region. Obviously, crustal earthquakes are dominant in the seismicity of the region, but it is also clear that mantle earthquakes make a significant contribution to it. The fact that their share in the total number of earthquakes is much smaller than the share of crustal earthquakes, suggests that the crust is more rigid and fragile than the upper mantle. 


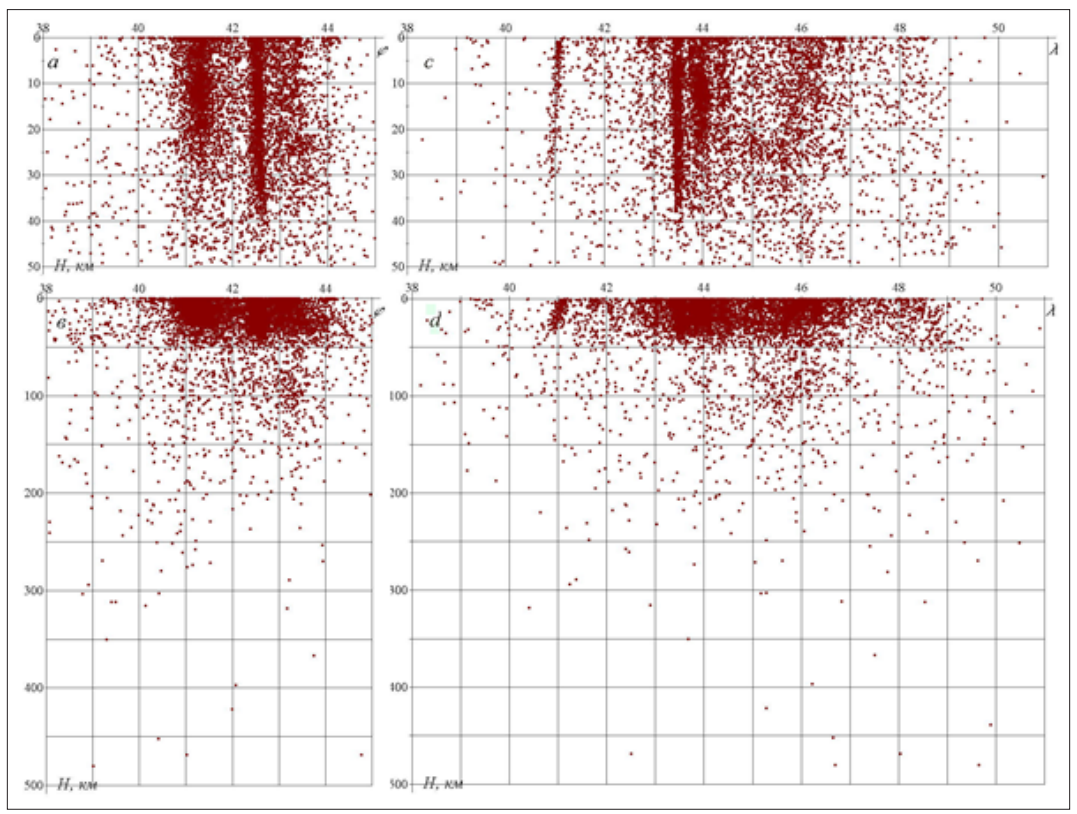

Figure 2: Distribution of hypocenters of earthquakes in the Caucasus in longitudinal (a) and (b) and latitudinal (c) and (d) planes for the period 1971-2015.inance-area. 